\title{
Article \\ Human Nonmercaptalbumin Is a New Biomarker of Motor Function
}

\author{
Sadayuki Ito ${ }^{1}$, Hiroaki Nakashima ${ }^{1, *}$, Kei Ando ${ }^{1}$, Kazuyoshi Kobayashi ${ }^{1}$, Masaaki Machino ${ }^{1}$, Taisuke Seki ${ }^{1}$, \\ Shinya Ishizuka ${ }^{1}$, , Shunsuke Kanbara ${ }^{1}$, Taro Inoue ${ }^{1}$, Hiroyuki Koshimizu ${ }^{1}$, Ryosuke Fujii ${ }^{2} \mathbb{D}_{\text {, Hiroya Yamada }}{ }^{3}$, \\ Yoshitaka Ando ${ }^{4}$, Jun Ueyama ${ }^{5}$, Takaaki Kondo ${ }^{5}$ D , Koji Suzuki ${ }^{2}$, Yukiharu Hasegawa ${ }^{6}$ and Shiro Imagama ${ }^{1}$
}

check for updates

Citation: Ito, S.; Nakashima, H.; Ando, K.; Kobayashi, K.; Machino, M.; Seki, T.; Ishizuka, S.; Kanbara, S.; Inoue, T.; Koshimizu, H.; et al. Human Nonmercaptalbumin Is a New Biomarker of Motor Function. J. Clin. Med. 2021, 10, 2464. https:// doi.org/10.3390/jcm10112464

Academic Editor: Johannes

C. Reichert

Received: 24 April 2021

Accepted: 31 May 2021

Published: 2 June 2021

Publisher's Note: MDPI stays neutral with regard to jurisdictional claims in published maps and institutional affiliations.

Copyright: (c) 2021 by the authors. Licensee MDPI, Basel, Switzerland. This article is an open access article distributed under the terms and conditions of the Creative Commons Attribution (CC BY) license (https:// creativecommons.org/licenses/by/ $4.0 /)$.
1 Department of Orthopaedic Surgery, Graduate School of Medicine,

Nagoya University, Nagoya 466-8560, Japan; sadaito@med.nagoya-u.ac.jp (S.I.); andokei@med.nagoya-u.ac.jp (K.A.); k_koba1@f2.dion.ne.jp (K.K.); masaaki_machino_5445_2@yahoo.co.jp (M.M.); taiseki@med.nagoya-u.ac.jp (T.S.); shinyai@med.nagoya-u.ac.jp (S.I.); shunaly0108@gmail.com (S.K.); bluesdrivemonster@hotmail.com (T.I.); love_derika@yahoo.co.jp (H.K.); imagama@med.nagoya-u.ac.jp (S.I.)

2 Department of Preventive Medical Sciences, School of Medical Sciences, Fujita Health University, Toyoake 470-1192, Japan; rfujii@fujita-hu.ac.jp (R.F.); ksuzuki@fujita-hu.ac.jp (K.S.)

3 Department of Hygiene, School of Medicine, Fujita Health University, Toyoake 470-1192, Japan; hyamada@fujita-hu.ac.jp

4 Department of Biomedical and Analytical Sciences, School of Medical Sciences, Fujita Health University, Toyoake 470-1192, Japan; yando@fujita-hu.ac.jp

5 Department of Pathophysiological Laboratory Sciences, Graduate School of Medicine, Nagoya University, Nagoya 466-8560, Japan; ueyama@met.nagoya-u.ac.jp (J.U.); taka@met.nagoya-u.ac.jp (T.K.)

6 Department of Rehabilitation, Kansai University of Welfare Science, Osaka 582-0026, Japan; hasegawa@tamateyama.ac.jp

* Correspondence: hirospine@med.nagoya-u.ac.jp

Abstract: The ratio of human nonmercaptalbumin (HNA) and reduced albumin (HMA) may be a new marker for oxidative stress. Locomotive syndrome (LS) is reduced mobility due to impairment of locomotive organs. We investigated whether the HNA/HMA ratio could be a new biomarker of LS. This study included 306 subjects (mean age $64.24 \pm 10.4$ years) who underwent LS tests, grip strength, walking speed, and tests for HNA and HMA. Oxidative stress was measured by the ratio of HMA $(\mathrm{f}(\mathrm{HMA})=(\mathrm{HMA} /(\mathrm{HMA}+\mathrm{HNA}) \times 100))$, and the subjects were divided into normal (N group; $\mathrm{f}[\mathrm{HMA}] \geq 70 \%$ ) and low (L group; $\mathrm{f}[\mathrm{HMA}]<70 \%$ ) groups. There were 124 non-elderly ( $<65$ years) and 182 elderly subjects ( $\geq 65$ years). There were no significant differences in LS, grip strength, and walking speed between the $\mathrm{L}$ and $\mathrm{N}$ groups in the non-elderly subjects. However, significant differences were found in the elderly subjects. In logistic regression analysis, there was an association between $\mathrm{f}(\mathrm{HMA})$ and the LS severity at older ages. LS in the elderly is associated with a decline in HMA and, thus, an increase in oxidative stress. Thus, $\mathrm{f}(\mathrm{HMA})$ is a new biomarker of LS.

Keywords: human nonmercaptalbumin; reduced albumin; oxidative stress; locomotive syndrome

\section{Introduction}

The majority of developed countries have an aging population [1], and the number of people requiring support and care in their daily lives due to musculoskeletal disorders is increasing [2]. Locomotive syndrome (LS), which is a condition of reduced mobility due to impairment of locomotive organs, was proposed by the Japanese Orthopedic Association (JOA) as an overarching term for this condition [2,3]. LS has received worldwide attention for an assessment of the motor function in motor diseases [4]. LS is associated with a significantly lower quality of life (QOL) [5] and a shorter life expectancy. Prevention of LS has long been advocated for maintaining and improving physical function in middle-aged and elderly people [6]. 
Oxidative stress reflects the imbalance of reactive oxidative species and antioxidant defenses and plays an important role in the decline of body functions in old age [7-9]. Elevated oxidative stress induces apoptosis of skeletal muscle [10], abnormality in neuromuscular junctions [11] and impaired mitochondrial function [12], resulting in decreased muscle performance, one of the major determinants of exercise capacity [13]. A recent systematic review of older adults has shown an association between increased oxidative stress and physical frailty [14]. Given that oxidative stress is one of the origins of agerelated decline in functional reserve, the use of biomarkers that reflect the redox status of the body may allow early identification of individuals at risk of functional decline due to musculoskeletal disease. The human serum albumin (HSA) cysteine-34 accounts for about $80 \%$ of the extracellular free thiols and is a major extracellular antioxidant [15]. Thus, HSA has been considered an important scavenger of reactive oxidative species, for example hydroxyl radical and hydrogen peroxide [16], but there are reports of differing antioxidative effects of HSA depending on its chemical structure. For example, Cys-34 residue functions as a universal antioxidant residue with excellent scavenging ability against a variety of reactive oxygen species, while Met residue may play an auxiliary role [17,18].

HSAs have been chemically classified into two major categories based on their redox status: human non-mercaptalbumin (HNA: oxidized form) and human mercaptalbumin (HMA: reduced form) [19]. Under oxidative stress, HMA changes to reversibly oxidized HNA-1 and highly oxidized HNA-2. Under oxidative stress, HMA buffers reactive oxidized species and turns them into HNAs; therefore, the proportion of HMA in HSA (f(HMA)) has been considered a biomarker reflecting the redox status of the human body [20]. Although the proportion of each HSA form is generally age- and disease-dependent, studies have shown that HMA, HNA-1, and HNA-2 account for $70-80 \%, 20-30 \%$, and $2-5 \%$, respectively, of the total albumin in healthy young adults [21].

Several clinical studies have examined the relationship between the redox status of HSA and the severity and progression of hypertension [22,23], obesity [24], liver injury [25], renal function [26,27], anemia [28], and cardiovascular complications in patients on dialysis [29,30]. It is also associated with Diabetes Mellitus [31] and Alzheimer's disease [32].

Although limited epidemiological studies have analyzed the association between HSA redox status and motor function [33], this redox status might be a biomarker for LS. The purpose of this study was to evaluate the redox status of albumin in a middle-aged and elderly Japanese population, and to investigate its correlation with motor function, including LS.

\section{Materials and Methods}

\subsection{Study Participants}

The individuals surveyed were volunteers who underwent a municipal-supported health checkup in the town of Yakumo in 2016. The town of Yakumo has a population of about 17,000 of whom $28 \%$ are over 65 years old. More people are engaged in agriculture and fishing than in urban areas. This town has been conducting annual health checkups since 1982. Physical examinations include voluntary orthopedic and physical function tests, internal examinations, and psychological examinations, as well as a health-related QOL survey (SF-36) [34,35]. This study included all participants who completed an assessment of the LS risk stage. The exclusion criteria were: a history of spine or joint surgery, severe knee injury, severe hip osteoarthritis, history of hip or spine fractures, neuropathy, severe mental illness, diabetes, kidney or heart disease, non-fasting, severe impairment of walking or standing, and impairment of the central or peripheral nervous system.

Of the 555 participants who underwent health checks, 306 (128 men and 178 women) met the inclusion criteria. The research protocol was approved by the Human Research Ethics Committee and the University's Institutional Review Board (No. 2014-0207). All participants gave written informed consent prior to participation. The research procedure was carried out in accordance with the principles of the Declaration of Helsinki. 


\subsection{Examination of Motor Function}

Grip strength in the standing position was measured once for each hand with a handgrip dynamometer (Toei Light Co., Ltd., Saitama, Japan), and the mean value was used [36]. Subjects walked a straight $10 \mathrm{~m}$ course once at their fastest pace, and the time required to complete the course was recorded as the $10 \mathrm{~m}$ gait time [37].

\subsection{LS Stage Tests}

To evaluate the risk of LS, the JOA has proposed three tests: the two-step test, the stand-up test, and the 25-question geriatric locomotive function scale (GLFS-25) [2]. LS is categorized into stages 1 and 2, and these tests assess the degree of motor function and define the stages of LS. Stage 1 indicates that movement function has begun to decline, and stage 2 indicates that movement function has progressed towards a decline in mobility.

Three tests were conducted according to the JOA guidelines [2].

In the stand-up test, the ability to stand with a single- or double-leg stance from stools of heights, $40,30,20$, and $10 \mathrm{~cm}$, is evaluated. The grading of difficulty, from easy to difficult, is in the order of double-leg stance with $40,30,20$, and $10 \mathrm{~cm}$ stools, followed by single-leg stance with $40,30,20$, and $10 \mathrm{~cm}$. The test result is expressed as the minimum height of the stool that the subject was able to stand up from.

In the two-step test, a physical therapist measured the length of two steps from the starting line to the tip of the toe. Scores were calculated by normalizing the maximum length of two steps by height.

The GLFS-25 is a self-reported comprehensive survey that refers to the previous month [38]. The scale consists of four questions about pain, 16 questions about Activities of Daily Living (ADL), three questions about social functioning, and two questions about mental status. Each item was graded from no disability (0 points) to severe disability (4 points).

We defined LS0, 1, 2 as follows:

The subject is categorized as Stage 0 if all three of the conditions are met as follows:

1. Stand-up test, ability to stand on one-leg from a 40-cm-high seat (both legs).

2. Two-step test, $>1.3$.

3. 25-question GLFS score, $<7$.

LS1

The subject is categorized as Stage 1 if any of the three conditions are met as follows:

1. Stand-up test, difficulty in one-leg standing from a 40-cm-high seat (either leg).

2. Two-step test, $<1.3$.

3. 25-question GLFS score, $\geq 7$.

LS2

The subject is categorized as Stage 2 if any of the three conditions are met as follows:

1. Stand-up test, difficulty in standing from a 20-cm-high seat using both legs.

2. Two-step test, $<1.1$.

3. 25-question GLFS score, $\geq 16$.

\subsection{Measurements of HSA}

During the checkup, fasting blood samples were collected through venipuncture and centrifuged within $1 \mathrm{~h}$ of sampling. Serum samples were stored at $-80^{\circ} \mathrm{C}$ until the assay was performed. Routine biochemical analyses were performed in the laboratory of the Yakumo Town Hospital. Interpersonal measurements of height and weight were taken to calculate the body mass index (BMI, $\left.\mathrm{kg} / \mathrm{m}^{2}\right)$.

The determination of HSA, HNA, and HMA using high performance liquid chromatography (HPLC) with an ultraviolet detector has been reported by Sogami et al. [39]. In this study, the HPLC-post-column bromocresol green (BCG) method was used, which was 
engineered to ensure that serum uric acid and bilirubin did not interfere with chromatographic peaks [40]. Frozen serum samples were thawed at room temperature and filtered through a Mini-UniPrep syringe-less filter (Agilent, Tokyo, Japan); HPLC was performed and reacted with BCG reagents to separate HMA and HNA detected at a $620 \mathrm{~nm}$ wavelength. The sample volume injected into the HPLC was $5 \mu \mathrm{L}$. The mobile phase reagent consisted of $\mathrm{N}$-methylpiperazine- $\mathrm{HCl}$ buffer ( $\mathrm{pH} 4.5$ ), $40 \mathrm{mM} \mathrm{Na}_{2} \mathrm{SO}_{4}$, and $3 \%$ ethanol; the BCG reagent consisted of $150 \mathrm{mM}$ citric acid, 3\% Brigi 35, and $0.3 \mathrm{mM}$ BCG. For all experiments, distilled water deionized to $18 \mathrm{~m} \Omega$ using the Millipore Milli-Q System (Millipore Co., Bedford, MA, USA) was used.

The HPLC system used in this study was the Hitachi Lacrom Ice System (Hitachi, Tokyo, Japan), which consisted of an isocratic pump (L-2130), an auto-injector (L-2200), and a column oven (L-2300). Chromatograms were obtained using a photodiode array detection system (model L-2455). A Shodex Asahipak GS-570 GS column $(100 \mathrm{~mm} \times 7.5 \mathrm{~mm}$ ID) was used to separate the HSA components before sample injection.

In the present experiment, the peak of HNA-2 was not sufficiently quantified, and its peak area was not considered in subsequent analyses. To numerically assess the redox state of HSA from the HPLC profile, $\mathrm{f}(\mathrm{HMA})$, which represents the ratio of the peak area of HMA to the peak area of HSA, has been used in previous similar studies [41]. Hence, we followed these reports for the present study.

The $\mathrm{f}(\mathrm{HMA})$ was calculated using the following equation: $\mathrm{f}(\mathrm{HMA})=\mathrm{HMA}$ area $/(\mathrm{HMA}$ area + HNA area) $\times 100$.

Previous studies have demonstrated that $\mathrm{f}(\mathrm{HMA})$ accounts for $70-80 \%$ of the total albumin in a healthy young adult [42]. Therefore, the cut-off value of $f(H M A)$ was determined to be $70 \%$. We divided the participants into the normal (N, $\mathrm{f}(\mathrm{HMA}) \geq 70 \%$ ) and lower $(\mathrm{L}, \mathrm{f}(\mathrm{HMA})<70 \%)$ oxidative stress groups.

\subsection{Statistical Analysis}

Continuous variables were expressed as mean \pm standard deviation (SD). We compared continuous variables of the L group to those of the $\mathrm{N}$ group using the student $\mathrm{t}$-test, and categorical variables of the $\mathrm{L}$ group to those of the $\mathrm{N}$ group using the Chi-squared test. Logistic regression analysis was performed to evaluate important risk factors of elevated oxidative stress, as defined by $\mathrm{f}(\mathrm{HMA})<70 \%$ : L group. The dependent variable was $\mathrm{N}$ versus $\mathrm{L}$ groups. Following univariable analysis, variables that yielded a $p$-value $<0.20$ were included in the multivariable analysis.

Each analysis was done separately for the under-65 (non-elderly) and the over-65 (elderly) groups.

All statistical analyses were performed using SPSS Statistics v.22.0 software for Mac (IBM Corp., Armonk, NY, USA). A $p$-value $<0.05$ was considered significant in all analyses.

\section{Results}

Table 1 shows the participant characteristics. The participants had an average age of $64.24 \pm 10.4$ years; 128 were male and 178 were female. The mean albumin serum level was $4.39 \pm 0.25(\mathrm{~g} / \mathrm{dL})$; The mean $\mathrm{f}(\mathrm{HMA})$ was $69.49 \pm 7.02 \%$; there were 151 and 155 participants in the $\mathrm{N}$ and L groups, respectively. With respect to the severity of LS, 118 participants (38.6\%) were at no risk (stage 0$), 116$ (37.9\%) were stage 1, and $72(23.5 \%)$ were stage 2 [43]. 
Table 1. Demographics and clinical characteristics.

\begin{tabular}{cccc}
\hline Characteristics & Total $(\boldsymbol{n = 3 0 6})$ & Non-Elderly $(\boldsymbol{n}=\mathbf{1 2 4})$ & Elderly $(\boldsymbol{n}=\mathbf{1 8 2})$ \\
\hline male $/$ female & $128 / 178$ & $40 / 84$ & $88 / 94$ \\
Age $($ years old $)$ & $64.24 \pm 10.4$ & $54.19 \pm 7.34$ & $71.19 \pm 5.24$ \\
Height $(\mathrm{cm})$ & $157.88 \pm 8.15$ & $159.56 \pm 8.16$ & $156.71 \pm 7.97$ \\
Weight $(\mathrm{kg})$ & $58.84 \pm 11.35$ & $60.04 \pm 12.61$ & $58.02 \pm 10.36$ \\
BMI $\left(\mathrm{kg} / \mathrm{cm}^{2}\right)$ & $23.5 \pm 3.48$ & $23.44 \pm 3.73$ & $23.54 \pm 3.31$ \\
grip strength $(\mathrm{kg})$ & $27.06 \pm 8.88$ & $27.28 \pm 9.47$ & $26.9 \pm 8.46$ \\
gait speed $(\mathrm{m} / \mathrm{s})$ & $1.88 \pm 0.29$ & $1.94 \pm 0.28$ & $1.84 \pm 0.29$ \\
Albumin $(\mathrm{g} / \mathrm{dL})$ & $4.39 \pm 0.25$ & $4.42 \pm 0.25$ & $4.36 \pm 0.26$ \\
f(HMA) $(\%)$ & $69.49 \pm 7.02$ & $72.96 \pm 5.86$ & $67.09 \pm 6.76$ \\
N/L & $151 / 155$ & $84 / 40$ & $67 / 115$ \\
Stage of LS $(0 / 1 / 2)$ & $118 / 116 / 72$ & $52 / 50 / 22$ & $66 / 66 / 50$ \\
\hline BII
\end{tabular}

BMI: body mass index; $\mathrm{f}(\mathrm{HMA})$ : fraction of human mercaptalbumin; $\mathrm{f}(\mathrm{HMA})=\mathrm{HMA}$ area/(HMA area + HNA area); HMA: human mercaptalbumin; N: participants with $\mathrm{f}(\mathrm{HMA})$ of $70 \%$ or more; L: participants with $\mathrm{f}(\mathrm{HMA})$ less than $70 \%$; LS: locomotive syndrome. Values are mean \pm SD for each group.

\subsection{Non-Elderly Participants}

The average age was $54.19 \pm 7.34$ years, and the mean $\mathrm{f}(\mathrm{HMA})$ was $72.96 \pm 5.86 \%$. Eighty-four $(67.7 \%)$ and $40(32.3 \%)$ subjects were considered to be in the $\mathrm{N}$ and L oxidative stress groups, respectively. In terms of LS, $52(41.9 \%), 50(40.3 \%)$, and 22 participants $(17.8 \%)$ were grouped into no risk (stage 0$)$, stage 1 , and stage 2 , respectively (Table 1 ). The average age was significantly higher in the L group $(\mathrm{N}: 53.42 \pm 7.5, \mathrm{~L}: 56.89 \pm 6.15$, $p<0.001$ ). Gender, height, weight, BMI, grip strength, and gait speed were not significantly different between the groups. There was no significant difference in the severity of LS between the $\mathrm{N}$ and $\mathrm{L}$ oxidative stress groups (stage 0: 41.7 and $42.5 \%$, stage 1: 40.5 and $40.0 \%$, and stage 2: 17.8 and $17.5 \%$ in the $\mathrm{N}$ and L groups, $p=0.90)($ Table 2$)$.

Table 2. The comparison of each parameter between the $\mathrm{N}$ and $\mathrm{L}$ groups in non-elderly participants.

\begin{tabular}{cccc}
\hline Non-Elderly $(\boldsymbol{n}=\mathbf{1 2 4})$ & N Group $(\boldsymbol{n}=\mathbf{8 4})$ & L Group $(\boldsymbol{n}=\mathbf{4 0 )}$ & $\boldsymbol{p}$ \\
\hline male $/$ female & $32 / 52$ & $16 / 24$ & 0.304 \\
Age (years) & $53.42 \pm 7.5$ & $56.89 \pm 6.15$ & $<0.001$ \\
Height $(\mathrm{cm})$ & $160.76 \pm 7.87$ & $159.47 \pm 8.45$ & 0.579 \\
Weight $(\mathrm{kg})$ & $59.28 \pm 11.48$ & $61.8 \pm 12.28$ & 0.283 \\
BMI $\left(\mathrm{kg} / \mathrm{cm}^{2}\right)$ & $22.9 \pm 3.52$ & $24.27 \pm 3.84$ & 0.69 \\
grip strength $(\mathrm{kg})$ & $28.44 \pm 9.55$ & $27.57 \pm 9.63$ & 0.639 \\
gait speed $(\mathrm{m} / \mathrm{s})$ & $1.95 \pm 0.27$ & $1.92 \pm 0.31$ & 0.623 \\
Stage of LS $(0 / 1 / 2)$ & $35 / 34 / 15$ & $17 / 16 / 7$ & 0.904 \\
\hline
\end{tabular}

BMI: body mass index; $N$ group: participants with $\mathrm{f}(\mathrm{HMA})$ of $70 \%$ or more; L group: participants with $\mathrm{f}(\mathrm{HMA})$ less than $70 \%$; LS: locomotive syndrome. Values are mean \pm SD for each group.

\subsection{Elderly Participants}

The average age was $71.19 \pm 5.24$ years, and the mean $\mathrm{f}(\mathrm{HMA})$ was $67.09 \pm 6.76 \%$. Sixty-seven (36.8\%) and $115(63.2 \%)$ subjects were categorized in the $\mathrm{N}$ and $\mathrm{L}$ oxidative stress groups, respectively. In terms of LS, 66 (36.3\%), 66 (36.3\%), and $50(27.4 \%)$ participants were grouped into stage 0 , stage 1 , and stage 2 , respectively (Table 1 ).

Age and BMI were not significantly different between the $\mathrm{N}$ and $\mathrm{L}$ oxidative stress groups. There were significant differences in the percentage of LS in elderly participants (N: stage 0: $33(49.3 \%)$, stage 1: $21(31.3 \%)$, stage 2: $13(19.4 \%)$; L: stage 0: $33(28.7 \%)$, stage 1: $45(39.1 \%)$, stage 2: $37(32.2 \%) ; p=0.004)$. There were significant differences in gender, height, weight, grip strength, and gait speed in elderly participants $(p<0.001, p<0.001$, $p=0.018, p<0.001, p=0.002$, respectively) (Table 3 ). 
Table 3. The comparison of each parameter between the $\mathrm{N}$ and $\mathrm{L}$ groups in elderly participants.

\begin{tabular}{cccc}
\hline Elderly $(\boldsymbol{n}=\mathbf{1 8 2})$ & N Group $(\boldsymbol{n}=\mathbf{6 7})$ & L Group $(\boldsymbol{n}=\mathbf{1 1 5})$ & $p$ \\
\hline male $/$ female & $40 / 27$ & $47 / 68$ & $<0.001$ \\
Age $($ years $)$ & $69.95 \pm 4.41$ & $71.55 \pm 5.63$ & 0.057 \\
Height $(\mathrm{cm})$ & $159.13 \pm 7.94$ & $155.32 \pm 7.81$ & $<0.001$ \\
Weight $(\mathrm{kg})$ & $59.11 \pm 10.2$ & $57.37 \pm 10.43$ & 0.018 \\
BMI $\left(\mathrm{kg} / \mathrm{cm}^{2}\right)$ & $23.25 \pm 3$ & $23.69 \pm 3.42$ & 0.930 \\
grip strength $(\mathrm{kg})$ & $28.35 \pm 8.51$ & $25.8 \pm 8.39$ & $<0.001$ \\
gait speed $(\mathrm{m} / \mathrm{s})$ & $1.92 \pm 0.24$ & $1.78 \pm 0.3$ & 0.002 \\
Stage of LS $(0 / 1 / 2)$ & $33 / 21 / 13$ & $33 / 45 / 37$ & 0.004 \\
\hline
\end{tabular}

BMI: body mass index; $N$ group: participants with $\mathrm{f}(\mathrm{HMA})$ of $70 \%$ or more; L group: participants with f(HMA) less than $70 \%$; LS: locomotive syndrome. Values are mean \pm SD for each group.

Since there were several factors with significant differences, they were examined as covariates for risk factors for elevated oxidative stress, as defined by $\mathrm{f}(\mathrm{HMA})>70 \%$ : L group in logistic regression analysis, which found only LS as a risk factor for elevated oxidative stress (OR $0.515,95 \%$ confidence interval, 95\% CI: $0.281-0.943, p=0.032$ ) (Table 4). As the LS stage increased by 1 , the risk of becoming $L$ increased by 0.515 times.

Table 4. Logistic regression analysis for risk factors of the elevation of oxidative stress (L group) in elderly participants.

\begin{tabular}{|c|c|c|c|c|c|c|c|}
\hline Elderly & B & SE & Wald & df & $p$ & OR & $95 \%$ CI \\
\hline male/female & 0.031 & 0.709 & 0.002 & 1 & 0.966 & 1.031 & $0.257-4.136$ \\
\hline Age (years) & -0.05 & 0.042 & 1.412 & 1 & 0.235 & 0.951 & $0.876-1.033$ \\
\hline Height $(\mathrm{cm})$ & 0.079 & 0.042 & 3.482 & 1 & 0.062 & 1.082 & $0.996-1.175$ \\
\hline Weight (kg) & -0.005 & 0.025 & 0.043 & 1 & 0.836 & 0.995 & $0.947-1.045$ \\
\hline $\begin{array}{l}\text { grip strength } \\
(\mathrm{kg})\end{array}$ & -0.08 & 0.755 & 0.011 & 1 & 0.915 & 0.923 & $0.21-4.054$ \\
\hline $\begin{array}{l}\text { gait speed } \\
(\mathrm{m} / \mathrm{s})\end{array}$ & -0.003 & 0.039 & 0.007 & 1 & 0.932 & 0.997 & $0.924-1.075$ \\
\hline $\begin{array}{l}\text { Stage of LS } \\
(0 / 1 / 2)\end{array}$ & -0.663 & 0.309 & 4.62 & 1 & 0.032 & 0.515 & $0.281-0.943$ \\
\hline
\end{tabular}

\section{Discussion}

There have been several reports of the association between $\mathrm{f}(\mathrm{HMA})$, a marker of oxidative stress, and chronic diseases [16]. However, few reports have indicated its association with motor function [33]. Furthermore, to our knowledge, this is the first study to report on the association between $\mathrm{f}(\mathrm{HMA})$ and LS. The present study indicated that subjects with more severe LS stages had higher oxidative stress as assessed by f(HMA) levels in the elderly group, where oxidative stress was associated with a decline in locomotive function. The $\mathrm{f}(\mathrm{HMA})$ ratio could be a new biomarker associated with LS in elderly subjects.

Oxidative stress reflects the imbalance of reactive oxidative species and antioxidant defenses, and it plays an important role in the decline of body functions [7]. It has been reported that oxidative stress is associated with chronic diseases, including hypertension, obesity, liver injury, renal function, anemia, and cardiovascular complications [30]. Furthermore, increased oxidative stress in the elderly might be associated with a deterioration in motor function as increased oxidative stress reduces walking speed in elderly women [33]. This study concurred, showing increased oxidative stress and reduced motor functions, such as grip strength and walking speed, in elderly people, which worsened the degree of impairment of locomotion.

There are several possible mechanisms to explain the association between $\mathrm{f}(\mathrm{HMA})$ levels and motor performance in LS. Oxidative stress is associated with muscle function through several pathways, including changes in neuromuscular junctions, reduced muscle 
energy metabolism, and reduced calcium release from the endoplasmic reticulum [11]. Another possible mechanism is muscle atrophy from increased proteolysis and decreased protein synthesis due to increased oxidative stress [11]. Oxidative stress has been reported to impair skeletal muscle as well as cardiovascular energy metabolism [11]. The association between $\mathrm{f}(\mathrm{HMA})$ and exercise capacity may be explained by the effect of oxidative stress on these systemic factors that determine exercise capacity.

In multivariate analysis, $\mathrm{f}(\mathrm{HMA})$ was associated with locomotion rather than simple motor functions, such as grip strength and gait, in the elderly group. LS is the concept of functional decline due to problems in bone, cartilage, muscle, and nerves [44], and $\mathrm{f}(\mathrm{HMA})$ may be related to abnormalities in these motor organs. However, an association between $\mathrm{f}(\mathrm{HMA})$ and decline in motor function or LS was not found in the non-elderly. The simple increase in oxidative stress does not affect motor function, but long-term exposure to oxidative stress, such as with age-related chronic inflammation, may be associated with a functional decline [45].

LS is a condition that requires nursing care. As it is a motor disease that is expected to improve with locomotion training, early detection leads to the preclusion of unnecessary nursing care [44]. In the current study, the oxidative stress marker f(HMA) was found to be associated with the degree of LS, and it may therefore be a new biomarker for the early detection of LS. If this is confirmed, it will be possible to intervene in LS from an early stage, resulting in nursing care being unnecessary. Furthermore, as exercise testing to diagnose LS is difficult in the limited time in an outpatient setting, if $\mathrm{f}(\mathrm{HMA})$ becomes a biomarker for suspected LS, it could provide a simple objective diagnostic modality for LS.

The modifiability of $\mathrm{f}(\mathrm{HMA})$ by intervention, and its responsiveness to changes in motor performance, need to be investigated in future studies. Supplementation with branched-chain amino acids is a potential intervention to increase f(HMA) levels. A previous study in patients with cirrhosis showed that administration of branched-chain amino acids increased f(HMA) [19]. LS may be improved by nutritional therapies that improve $\mathrm{f}(\mathrm{HMA})$, which may be a potential new treatment other than exercise therapy. There is scope to consider the link between LS, $\mathrm{f}(\mathrm{HMA})$, and nutritional status.

It may also be possible that the exercise regimens reported so far to improve LS may improve $\mathrm{f}(\mathrm{HMA})$ and reduce oxidative stress. Therefore, the results of this study may provide a basis for the hypothesis that exercise therapy, as previously described, improves systemic diseases caused by oxidative stress [46].

This study has several potential limitations. First, the participants were middle-aged and elderly people who lived in a relatively rural area, where many had jobs in agriculture or fishing. Thus, the lifestyle of these subjects differed from that of people in an urban environment. Furthermore, the participants attended for annual health examinations, which suggests that they may be more health conscious than other people. Second, this was a cross-sectional, single-center study. In the future, longitudinal and multicenter collaborative research will be needed to verify our findings. Finally, the specificity of $\mathrm{f}(\mathrm{HMA})$ as a biomarker of LS could not be discussed, because other biomarkers related to oxidative stress were not measured. Nevertheless, the present study still has a clinical application, by indicating that the redox state of HSA might serve as a biomarker for LS.

\section{Conclusions}

In conclusion, this study demonstrated that $\mathrm{f}(\mathrm{HMA})$, a marker for the redox state of HSA, correlated with the severity of LS in elderly people. Thus, we suggest that f(HMA) could be a novel biomarker of LS.

Author Contributions: Conceptualization, S.I. (Sadayuki Ito); methodology, S.I. (Sadayuki Ito); software, R.F.; validation, R.F., H.Y., Y.A., J.U., T.K., K.S.; formal analysis, S.I. (Sadayuki Ito); investigation, S.I. (Sadayuki Ito), H.N., K.A., K.K., T.S., S.I. (Shinya Ishizuka), M.M., S.K., T.I., H.K., R.F., H.Y., Y.A., J.U., T.K., K.S., Y.H. and S.I. (Shiro Imagama); resources, S.I. (Sadayuki Ito), H.N., K.A., K.K., T.S., S.I. (Shinya Ishizuka), M.M., S.K., T.I., H.K., R.F., H.Y., Y.A., J.U., T.K., K.S., Y.H. and S.I. (Shiro Imagama); data curation, S.I. (Sadayuki Ito); writing-original draft preparation, S.I. (Sadayuki Ito); 
writing—review and editing, S.I. (Sadayuki Ito) and H.N.; supervision, S.I. (Shiro Imagama); project administration, H.N. All authors have read and agreed to the published version of the manuscript.

Funding: This research did not receive any specific grant from funding agencies in the public, commercial, or not-for-profit sectors.

Institutional Review Board Statement: The research protocol was approved by the Human Research Ethics Committee and the University's Institutional Review Board (No. 2014-0207). All participants gave written informed consent prior to participation. The research procedure was carried out in accordance with the principles of the Declaration of Helsinki.

Informed Consent Statement: All participants gave written informed consent prior to participation.

Data Availability Statement: The data of health checkups used to support the findings of this study are available from the corresponding author upon request.

Acknowledgments: We are grateful to the staff of the Comprehensive Health Care Program held in Yakumo, Hokkaido, and Aya Henmi and Hiroko Ino of Nagoya University for their assistance throughout this study.

Conflicts of Interest: The authors declare that there is no conflict of interest regarding the publication of this paper.

\section{References}

1. Preston, S.H.; Stokes, A. Sources of population aging in more and less developed countries. Popul. Dev Rev. 2012, 38, 221-236. [CrossRef] [PubMed]

2. Nakamura, K.; Ogata, T. Locomotive Syndrome: Definition and Management. Clin. Rev. Bone Miner. Metab. 2016, 14, 56-67. [CrossRef]

3. Nakamura, K. The concept and treatment of locomotive syndrome: Its acceptance and spread in Japan. J. Orthop. Sci. 2011, 16, 489-491. [CrossRef] [PubMed]

4. Yi, H.-S.; Lee, S. Overcoming osteoporosis and beyond: Locomotive syndrome or dysmobility syndrome. Osteoporos. Sarcopenia 2018, 4, 77-78. [CrossRef] [PubMed]

5. Hirano, K.; Imagama, S.; Hasegawa, Y.; Ito, Z.; Muramoto, A.; Ishiguro, N. The influence of locomotive syndrome on health-related quality of life in a community-living population. Mod. Rheumatol 2013, 23, 939-944. [CrossRef] [PubMed]

6. Muramoto, A.; Imagama, S.; Ito, Z.; Hirano, K.; Ishiguro, N.; Hasegawa, Y. Spinal sagittal balance substantially influences locomotive syndrome and physical performance in community-living middle-aged and elderly women. J. Orthop. Sci. 2016, 21, 216-221. [CrossRef] [PubMed]

7. Saum, K.U.; Dieffenbach, A.K.; Jansen, E.H.; Schottker, B.; Holleczek, B.; Hauer, K.; Brenner, H. Association between oxidative stress and frailty in an elderly german population: Results from the ESTHER cohort study. Gerontology 2015, 61, 407-415. [CrossRef] [PubMed]

8. Venkataraman, K.; Khurana, S.; Tai, T.C. Oxidative stress in aging-matters of the heart and mind. Int. J. Mol. Sci. 2013, 14, 17897-17925. [CrossRef]

9. Jenny, N.S. Inflammation in aging: Cause, effect, or both? Discov. Med. 2012, 13, 451-460.

10. Wang, D.; Yang, Y.; Zou, X.; Zhang, J.; Zheng, Z.; Wang, Z. Antioxidant apigenin relieves age-related muscle atrophy by inhibiting oxidative stress and hyperactive mitophagy and apoptosis in skeletal muscle of mice. J. Gerontol. A Biol. Sci. Med. Sci. 2020, 75, 2081-2088. [CrossRef]

11. Baumann, C.W.; Kwak, D.; Liu, H.M.; Thompson, L.V. Age-induced oxidative stress: How does it influence skeletal muscle quantity and quality? J. Appl Physiol (1985) 2016, 121, 1047-1052. [CrossRef]

12. Liguori, I.; Russo, G.; Curcio, F.; Bulli, G.; Aran, L.; Della-Morte, D.; Gargiulo, G.; Testa, G.; Cacciatore, F.; Bonaduce, D.; et al. Oxidative stress, aging and diseases. Clin. Interv. Aging 2018, 13, 757-772. [CrossRef]

13. Gomes, M.J.; Martinez, P.F.; Pagan, L.U.; Damatto, R.L.; Cezar, M.D.M.; Lima, A.R.R.; Okoshi, K.; Okoshi, M.P. Skeletal muscle aging: Influence of oxidative stress and physical exercise. Oncotarget 2017, 8, 20428-20440. [CrossRef]

14. Soysal, P.; Isik, A.T.; Carvalho, A.F.; Fernandes, B.S.; Solmi, M.; Schofield, P.; Veronese, N.; Stubbs, B. Oxidative stress and frailty: A systematic review and synthesis of the best evidence. Maturitas 2017, 99, 66-72. [CrossRef]

15. Oettl, K.; Stauber, R.E. Physiological and pathological changes in the redox state of human serum albumin critically influence its binding properties. Br. J. Pharmacol. 2007, 151, 580-590. [CrossRef]

16. Zoellner, H.; Hofler, M.; Beckmann, R.; Hufnagl, P.; Vanyek, E.; Bielek, E.; Wojta, J.; Fabry, A.; Lockie, S.; Binder, B.R. Serum albumin is a specific inhibitor of apoptosis in human endothelial cells. J. Cell Sci. 1996, 109, 2571-2580. [CrossRef]

17. Iwao, Y.; Ishima, Y.; Yamada, J.; Noguchi, T.; Kragh-Hansen, U.; Mera, K.; Honda, D.; Suenaga, A.; Maruyama, T.; Otagiri, M. Quantitative evaluation of the role of cysteine and methionine residues in the antioxidant activity of human serum albumin using recombinant mutants. IUBMB Life 2012, 64, 450-454. [CrossRef] 
18. Quinlan, G.J.; Martin, G.S.; Evans, T.W. Albumin: Biochemical properties and therapeutic potential. Hepatology 2005, 41, 1211-1219. [CrossRef]

19. Setoyama, H.; Tanaka, M.; Nagumo, K.; Naoe, H.; Watanabe, T.; Yoshimaru, Y.; Tateyama, M.; Sasaki, M.; Watanabe, H.; Otagiri, M.; et al. Oral branched-chain amino acid granules improve structure and function of human serum albumin in cirrhotic patients. J. Gastroenterol. 2017, 52, 754-765. [CrossRef]

20. Soejima, A.; Kaneda, F.; Manno, S.; Matsuzawa, N.; Kouji, H.; Nagasawa, T.; Era, S.; Takakuwa, Y. Useful markers for detecting decreased serum antioxidant activity in hemodialysis patients. Am. J. Kidney Dis. 2002, 39, 1040-1046. [CrossRef]

21. Fujii, R.; Ueyama, J.; Aoi, A.; Ichino, N.; Osakabe, K.; Sugimoto, K.; Suzuki, K.; Hamajima, N.; Wakai, K.; Kondo, T. Oxidized human serum albumin as a possible correlation factor for atherosclerosis in a rural Japanese population: The results of the Yakumo Study. Environ. Health Prev. Med. 2018, 23, 1. [CrossRef]

22. Vaziri, N.D. Roles of oxidative stress and antioxidant therapy in chronic kidney disease and hypertension. Curr. Opin. Nephrol. Hypertens. 2004, 13, 93-99. [CrossRef] [PubMed]

23. Sato, K.; Dohi, Y.; Kojima, M.; Miyagawa, K.; Takase, H.; Katada, E.; Suzuki, S. Effects of ascorbic acid on ambulatory blood pressure in elderly patients with refractory hypertension. Arzneimittelforschung 2006, 56, 535-540. [CrossRef]

24. Keaney, J.F., Jr.; Larson, M.G.; Vasan, R.S.; Wilson, P.W.; Lipinska, I.; Corey, D.; Massaro, J.M.; Sutherland, P.; Vita, J.A.; Benjamin, E.J. Obesity and systemic oxidative stress: Clinical correlates of oxidative stress in the Framingham Study. Arterioscler. Thromb. Vasc. Biol. 2003, 23, 434-439. [CrossRef] [PubMed]

25. Oettl, K.; Birner-Gruenberger, R.; Spindelboeck, W.; Stueger, H.P.; Dorn, L.; Stadlbauer, V.; Putz-Bankuti, C.; Krisper, P.; Graziadei, I.; Vogel, W.; et al. Oxidative albumin damage in chronic liver failure: Relation to albumin binding capacity, liver dysfunction and survival. J. Hepatol. 2013, 59, 978-983. [CrossRef] [PubMed]

26. Terawaki, H.; Yoshimura, K.; Hasegawa, T.; Matsuyama, Y.; Negawa, T.; Yamada, K.; Matsushima, M.; Nakayama, M.; Hosoya, T.; Era, S. Oxidative stress is enhanced in correlation with renal dysfunction: Examination with the redox state of albumin. Kidney Int. 2004, 66, 1988-1993. [CrossRef] [PubMed]

27. Suzuki, Y.; Suda, K.; Matsuyama, Y.; Era, S.; Soejima, A. Close relationship between redox state of human serum albumin and serum cysteine levels in non-diabetic CKD patients with various degrees of renal function. Clin. Nephrol. 2014, 82, 320-325. [CrossRef]

28. Bissinger, R.; Bhuyan, A.A.M.; Qadri, S.M.; Lang, F. Oxidative stress, eryptosis and anemia: A pivotal mechanistic nexus in systemic diseases. FEBS J. 2019, 286, 826-854. [CrossRef]

29. Weiss, S.J. Tissue destruction by neutrophils. N. Engl. J. Med. 1989, 320, 365-376. [CrossRef]

30. Masudo, R.; Yasukawa, K.; Nojiri, T.; Yoshikawa, N.; Shimosaka, H.; Sone, S.; Oike, Y.; Ugawa, A.; Yamazaki, T.; Shimokado, K.; et al. Evaluation of human nonmercaptalbumin as a marker for oxidative stress and its association with various parameters in blood. J. Clin. Biochem. Nutr. 2017. [CrossRef]

31. Yasunari, K.; Maeda, K.; Nakamura, M.; Yoshikawa, J. Oxidative stress in leukocytes is a possible link between blood pressure, blood glucose and C-reacting protein. Hypertension 2002, 39, 777-780. [CrossRef]

32. Chen, Z.; Zhong, C. Oxidative stress in Alzheimer's disease. Neurosci. Bull. 2014, 30, 271-281. [CrossRef]

33. Ashikawa, H.; Adachi, T.; Ueyama, J.; Yamada, S. Association between redox state of human serum albumin and exercise capacity in older women: A cross-sectional study. Geriatr. Gerontol. Int. 2020, 20, 256-260. [CrossRef]

34. Imagama, S.; Hasegawa, Y.; Matsuyama, Y.; Sakai, Y.; Ito, Z.; Hamajima, N.; Ishiguro, N. Influence of sagittal balance and physical ability associated with exercise on quality of life in middle-aged and elderly people. Arch. Osteoporos. 2011, 6, 13-20. [CrossRef]

35. Tanaka, S.; Ando, K.; Kobayashi, K.; Hida, T.; Ito, K.; Tsushima, M.; Morozumi, M.; Machino, M.; Ota, K.; Suzuki, K.; et al. Utility of the Serum Cystatin C Level for Diagnosis of Osteoporosis among Middle-Aged and Elderly People. Biomed. Res. Int. 2019, 2019, 5046852. [CrossRef]

36. Muramoto, A.; Imagama, S.; Ito, Z.; Hirano, K.; Tauchi, R.; Ishiguro, N.; Hasegawa, Y. Threshold values of physical performance tests for locomotive syndrome. J. Orthop. Sci. 2013, 18, 618-626. [CrossRef]

37. Imagama, S.; Hasegawa, Y.; Ando, K.; Kobayashi, K.; Hida, T.; Ito, K.; Tsushima, M.; Nishida, Y.; Ishiguro, N. Staged decrease of physical ability on the locomotive syndrome risk test is related to neuropathic pain, nociceptive pain, shoulder complaints, and quality of life in middle-aged and elderly people-The utility of the locomotive syndrome risk test. Mod. Rheumatol. 2017, 27, 1051-1056. [CrossRef]

38. Seichi, A.; Hoshino, Y.; Doi, T.; Akai, M.; Tobimatsu, Y.; Iwaya, T. Development of a screening tool for risk of locomotive syndrome in the elderly: The 25-question Geriatric Locomotive Function Scale. J. Orthop. Sci. 2012, 17, 163-172. [CrossRef]

39. Sogami, M.; Era, S.; Nagaoka, S.; Kuwata, K.; Kida, K.; Miura, K.; Inouye, H.; Suzuki, E.; Hayano, S.; Sawada, S. HPLC-studies on nonmercapt-mercapt conversion of human serum albumin. Int. J. Pept. Protein Res. 1985, 25, 398-402. [CrossRef]

40. Ueyama, J.; Ishikawa, Y.; Kondo, T.; Motoyama, M.; Matsumoto, H.; Matsushita, T. A revised method for determination of serum mercaptalbumin and non-mercaptalbumin by high-performance liquid chromatography coupled with postcolumn bromocresol green reaction. Ann. Clin. Biochem. 2015, 52, 144-150. [CrossRef]

41. Maeda, K.; Yoshizaki, S.; Iida, T.; Terada, T.; Era, S.; Sakashita, K.; Arikawa, H. Improvement of the fraction of human mercaptalbumin on hemodialysis treatment using hydrogen-dissolved hemodialysis fluid: A prospective observational study. Ren. Replace. Ther. 2016, 2, 42. [CrossRef] 
42. Oettl, K.; Marsche, G. Redox state of human serum albumin in terms of cysteine-34 in health and disease. Methods Enzymol. 2010, 474, 181-195. [CrossRef] [PubMed]

43. Anraku, M.; Chuang, V.T.; Maruyama, T.; Otagiri, M. Redox properties of serum albumin. Biochim. Biophys. Acta 2013, 1830, 5465-5472. [CrossRef] [PubMed]

44. Ishibashi, H. Locomotive syndrome in Japan. Osteoporos Sarcopenia 2018, 4, 86-94. [CrossRef]

45. Michaud, M.; Balardy, L.; Moulis, G.; Gaudin, C.; Peyrot, C.; Vellas, B.; Cesari, M.; Nourhashemi, F. Proinflammatory cytokines, aging, and age-related diseases. J. Am. Med. Dir. Assoc. 2013, 14, 877-882. [CrossRef]

46. Arena, S.K.; Doherty, D.J.; Bellford, A.; Hayman, G. Effects of Aerobic Exercise on Oxidative Stress in Patients Diagnosed with Cancer: A Narrative Review. Cureus 2019, 11, e5382. [CrossRef] 